\title{
THE ACUTE EFFECTS OF SMOKING ON MYOCARDIAL PERFORMANCE IN PATIENTS WITH CORONARY ARTERIAL DISEASE
}

\author{
BY \\ BRIAN PENTECOST AND JOHN SHILLINGFORD \\ From the Medical Research Council's Cardiovascular Research Group and Department of Medicine, Postgraduate \\ Medical School of London, W.12 \\ Received September 20, 1963
}

It is common practice among physicians to urge patients with ischæmic heart disease to abstain from the use of tobacco. The exact scientific evidence on which this advice is based is not always clear although some papers offer suggestive evidence that smoking impairs the performance of the heart already damaged by disease of the coronary arteries (Pickering and Sanderson, 1945; Davis et al., 1956). With the development of a method to make frequent measurements of the cardiac output without discomfort or risk to the patient (Gabe, Tuckman, and Shillingford, 1962), it has been possible to make a quantitative assessment of cardiac performance before, during, and after smoking.

The purpose of this paper is to define more accurately the acute effects of smoking and nicotine on the circulation in those patients who are suffering from ischæmic heart disease, with or without myocardial infarction, and to compare them with the response in normal subjects.

\section{SuBJECTS AND METHODS}

Studies were carried out on 33 patients who can be conveniently divided into three groups: (1) 14 volunteers with a normal cardiovascular system; (2) 5 patients with angina but no evidence of myocardial infarction; and (3) 14 patients with historical, clinical, and electrocardiographic evidence of myocardial infarction. The distribution of patients between the three groups and their ages are shown in Table $I$. Although there is some overlap in the age ranges in the groups, the average age of the patients with myocardial ischæmia is higher than among the normal subjects. Among the 14 patients in the myocardial infarction group, 7 had had their infarction between three and six weeks before the smoking test was performed; the remaining 7 patients had their acute episode more than six months before the test. The majority of the subjects were men; there were two women in both the normal and myocardial infarction groups and one in the angina group.

All patients studied were smokers with the exception of one normal subject. Each patient was studied approximately two hours after lunch. No premedication was required but the nature of the procedure was fully explained to the patient, and each was allowed to rest quietly on a couch before measurements were commenced. The technique of measuring the cardiac output during cigarette smoking was as previously described from this laboratory by Irving and Yamamoto (1963). With the patient resting in the supine position, the couch being tilted $10^{\circ}$ feet down from the horizontal, frequent measurements were made of pulse rate, blood pressure by sphygmomanometry, and of the cardiac output relative to the resting state by the dye dilution method. For each estimation of the cardiac output, approximately $35 \mathrm{mg}$. of Coomassie Blue were used.

When a steady state had been reached the patient smoked a single cigarette, except for two patients in the post-infarction group who smoked pipes. No attempt was made to regulate the cigarette smoking with regard to either rate or depth of inhalation, but under the circumstances we found that patients tended to smoke fairly rapidly, and the average time taken to smoke one cigarette was 6 to 7 minutes. The cigarettes smoked were common commercial brands, and since the quantity of nicotine absorbed is little influenced 
TABLE I

Ages and Distribution of Patients Studied

\begin{tabular}{lll|r|c|c|c}
\hline & & \multirow{2}{*}{ No. } & \multicolumn{2}{|c}{ Age (yr.) } \\
\cline { 5 - 6 } & & & Average & Range \\
\hline Normal subjects &.. &. & 14 & $39 \cdot 5$ & 20 to 60 \\
Angina &.. &.. &. & 5 & $43 \cdot 4$ & 35 to 50 \\
Post-myocardial & infarction & 14 & $54 \cdot 1$ & 45 to 70 \\
\hline
\end{tabular}

TABLE II

Heart Rate and Mean Pressure Changes during Cigarette Smoking

\begin{tabular}{|c|c|c|c|c|c|}
\hline & \multirow{2}{*}{ No. } & \multicolumn{2}{|c|}{$\begin{array}{c}\text { Change in heart rate } \\
\text { (beats/min.) }\end{array}$} & \multicolumn{2}{|c|}{$\begin{array}{c}\text { Change in mean pressure } \\
(\mathrm{mm} . \mathrm{Hg})\end{array}$} \\
\hline & & Average & Range & Average & Range \\
\hline Normal subjects & 14 & +11 & +2 to +24 & $6 \cdot 2$ & 0 to +12 \\
\hline Angina & 5 & +7 & +2 to +10 & $5 \cdot 4$ & +1 to +8 \\
\hline Post-myocardial infarction & 14 & +6 & -2 to +19 & $9 \cdot 3$ & +1 to +20 \\
\hline
\end{tabular}

by filter tips, the patient was free to select tipped or untipped cigarettes. No denicotinized cigarettes were used. Observations were then continued throughout the period of cigarette smoking and for 5 to 10 minutes after. Changes in heart rate, blood pressure, and relative changes in stroke volume and cardiac output were recorded.

\section{RESULTS}

The smoking of one cigarette produced an increase in heart rate in all patients but one (Table II), the average increase being less in the post-infarction group. Similarly, an increase in the main arterial pressure occurred in all the patients with the exception of two among the normal group, who showed no change in pressure, and one patient with angina in whom there was a slight reduction in pressure (Table II). There was no significant difference in mean pressure change between the three groups.

The most interesting difference emerges upon comparison of the maximal cardiac output and stroke volume response to smoking (Fig. 1 and 2). The patients without evidence of cardiovascular disease all increased their cardiac output while smoking by an average of 27 per cent (range $+4-+50 \%$ ); those patients in the post-myocardial infarction group had an average increase in cardiac output of only 1 per cent, which is not significant (range $-23-+33 \%$ ). Comparison of the stroke volume showed the normal group to have an average increase of 10 per cent (range $-10-+35 \%$ ), while patients after myocardial infarction exhibited an average reduction of -8 per cent (range $-39-+27 \%$ ). Patients with angina alone occupied an intermediate position.

It has been necessary to analyse the data with respect to age. Among the normal subjects, age appears to have no influence upon the changes that occurred in pulse rate, mean pressure, or cardiac output. In the post-myocardial infarction group the resting pulse rate and the change in mean pressure are similarly uninfluenced by age, but the increase in pulse rate tends to be less among the elderly. The cardiac output and stroke volume more frequently show a reduction among the older patients (Fig. 3). It has not been possible to draw firm statistical conclusions on the effect of age in the post-infarction group because of the wide scatter of results. 


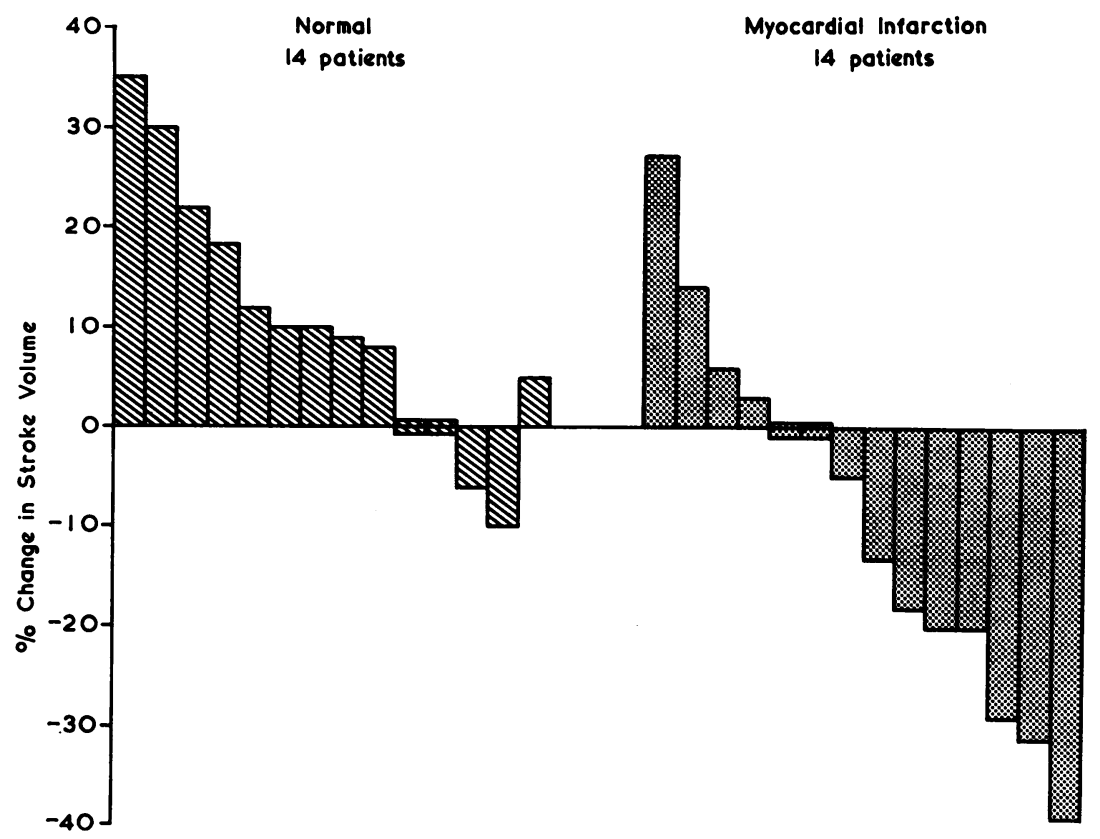

FIG. 1.-Cardiac output changes during cigarette smoking.

There is a difference between the stroke volume response in the normal subjects and in the postinfarction group $(p=0.06)$, and the difference is more significant when the minute output is considered $(p=0.003)$, reflecting the slighter increase in heart rate among the latter group.

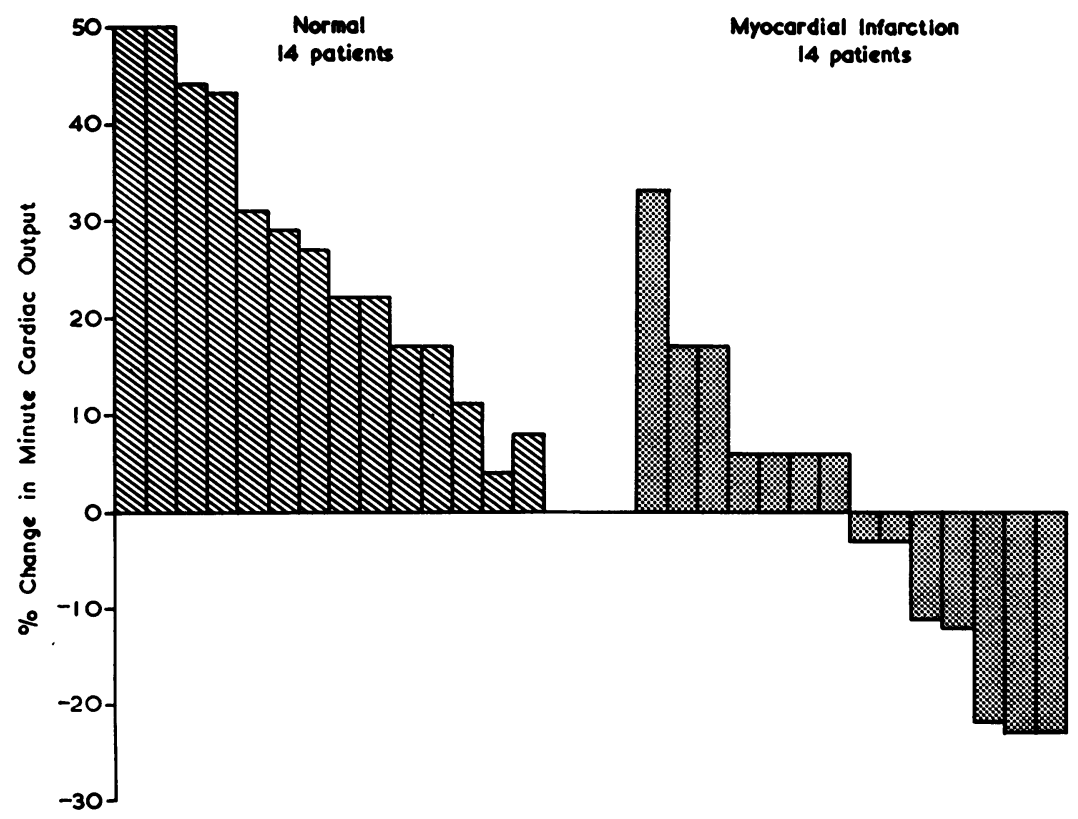

FIG. 2.-Stroke volume changes during cigarette smoking. 


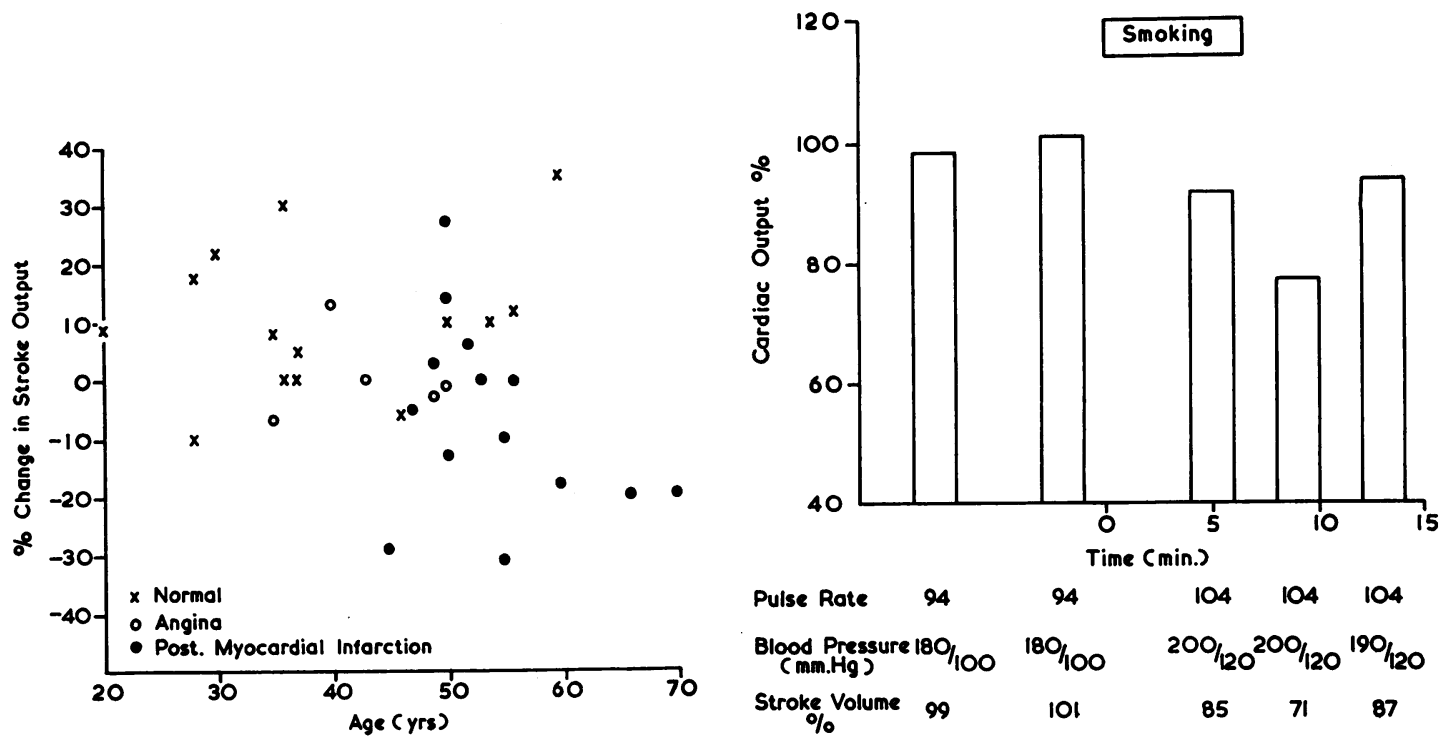

FIG. 3.-Stroke volume changes during smoking in relation to age.

Fig. 4.-Case 1, the effects of smoking one cigarette.

However, to analyse the post-myocardial infarction group as a homogeneous whole is hardly justifiable in view of the considerable variation in severity of ischæmic incidents and the degree of recovery from these episodes. More is to be learned from a study of some of the individual results.

The following case histories illustrate some responses encountered among patients who had suffered myocardial infarction.

\section{CASE RePORTS}

Case 1 (M.N. male, age 45 years). This patient had a six-year history of benign essential hypertension. He was taking methyldopa, $500 \mathrm{mg}$. t.d.s., and the blood pressure was $160 / 100 \mathrm{~mm}$. $\mathrm{Hg}$. He had had a posterior myocardial infarction seven months before the relevant admission and had subsequently suffered from angina pectoris on effort. Three weeks before admission there had been a particularly severe angina attack and there was electrocardiographic evidence of recent antero-lateral ischæmia. Apart from a soft apical third sound, there was no evidence of heart failure. The chest radiograph showed some left ventricular enlargement but this had not increased since the first infarction. On admission the patient was afebrile and the blood count, sedimentation rate, and transaminase estimations were normal. It was thought likely that the recent ischæmic episode had occurred during the attack of chest pain three weeks before admission. The patient was treated with bed-rest alone, and no further pain was experienced.

He had voluntarily reduced his cigarette smoking from 25 to 10 daily following his first infarct, because each cigarette caused a sensation of breathlessness and malaise.

The smoking test, performed three weeks after admission, showed that smoking one cigarette produced an increase in heart rate, a considerable rise in blood pressure from $180 / 100$ to $200 / 120 \mathrm{~mm}$. $\mathrm{Hg}$, and a reduction in cardiac output of 23 per cent and in stroke volume of 29 per cent (Fig. 4). The smoking test was discontinued because the patient felt vaguely unwell although dyspnœa was not experienced. There were no electrocardiographic changes during the period of cigarette smoking.

Case 2 (S.H. age 66 years). This patient, a pipe smoker with a long history of chronic bronchitis, had experienced dyspnœea and angina on effort for approximately one year. There had been a previous admission six months earlier when the patient had been in heart failure with pulmonary œedema. The current admission was necessitated by increasing angina on effort and on the morning of admission he had experienced a severe crushing retrosternal pain persisting for two to three hours. On examination a loud third sound was audible at the apex but there was no other evidence of heart failure. The blood pressure 

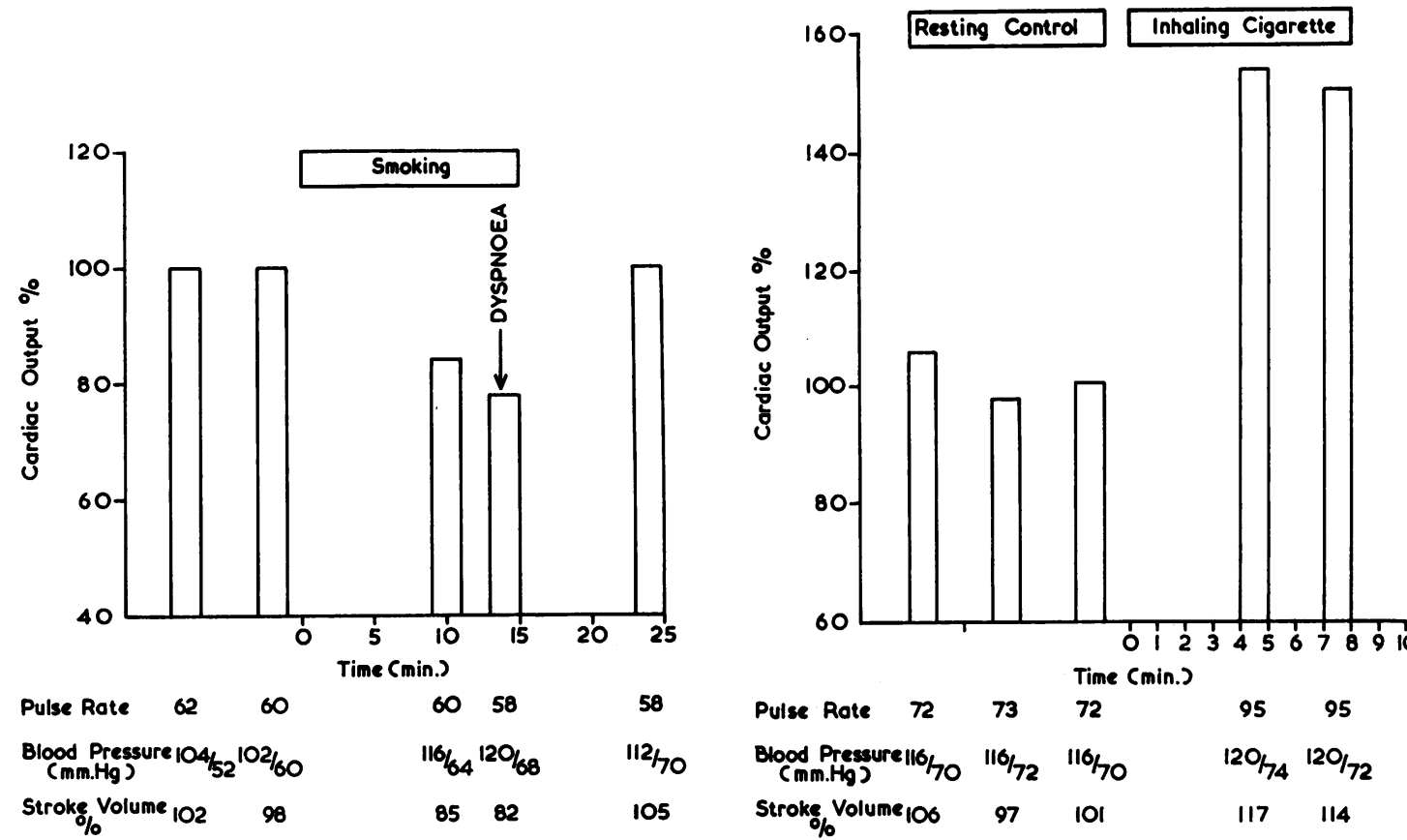

FIG. 5.-Case 2, the effects of pipe smoking.

FIG. 6. - Case 3, the effects of smoking one cigarette.

had fallen from the previous level of $180 / 100$ to $105 / 60 \mathrm{~mm}$. $\mathrm{Hg}$, and subsequently settled at $140 / 80 \mathrm{~mm}$. $\mathrm{Hg}$. The electrocardiogram showed no new evidence of a myocardial infarction, but on admission the patient had a low grade fever, a sedimentation rate of $36 \mathrm{~mm}$./hour (Westergren), and a serum glutamic-oxaloacetic transaminase level of 36 i.u., so that further myocardial necrosis was likely. Radiologically there was cardiac enlargement affecting both left and right ventricles, but there was no radiological evidence of pulmonary congestion.

The patient was treated with bed-rest, and the digitalis and chlorothiazide therapy were continued. The temperature and serum glutamic-oxaloacetic transaminase titre became normal within three days. There was no further chest pain and, apart from a period of multiple ventricular ectopic beats, his convalescence was uneventful. Three weeks later a smoking test was done. The patient drew quietly at his pipe for approximately 12 minutes and then experienced dyspnoa and malaise but no angina. At this time there was a considerable reduction in cardiac output (Fig. 5) and a delay in the appearance of the dye at the ear. The output rose rapidly when the patient stopped smoking and he became less breathless.

Case 3 (I.L. age 50 years). This man had been receiving treatment for hypertension for two years. Three days before admission he had the first of four severe anginal attacks at rest, each lasted around 5 minutes. On admission he was not shocked, and there was no evidence of heart failure. The electrocardiogram showed evidence of extensive anterior infarction. The blood pressure had fallen from the previous level of $240 / 110$ to $180 / 90 \mathrm{~mm}$. $\mathrm{Hg}$ and remained at this value. An uneventful recovery was made with no further anginal pain.

His cigarette consumption was 15 a day. Three weeks later, smoking one cigarette produced a substantial increase in heart rate and cardiac output, but a small rise in blood pressure (Fig. 6).

When the stroke volume is plotted against the change in mean blood pressure recorded during smoking (Fig. 7) all the patients with angina alone and many of those in the post-infarction group had a similar response to the normal patients, but in some cases the post-infarction group showed an unusual pattern involving a considerable reduction in cardiac output and stroke volume. In each of the five cases in which the stroke volume has fallen by 18 per cent or more of the resting value, the increase in mean pressure has been marked. Among the normal patients and those with angina, as well as among the several postinfarction patients who showed an increase in stroke volume, the rise in mean pressure was, in the majority of cases, less. 


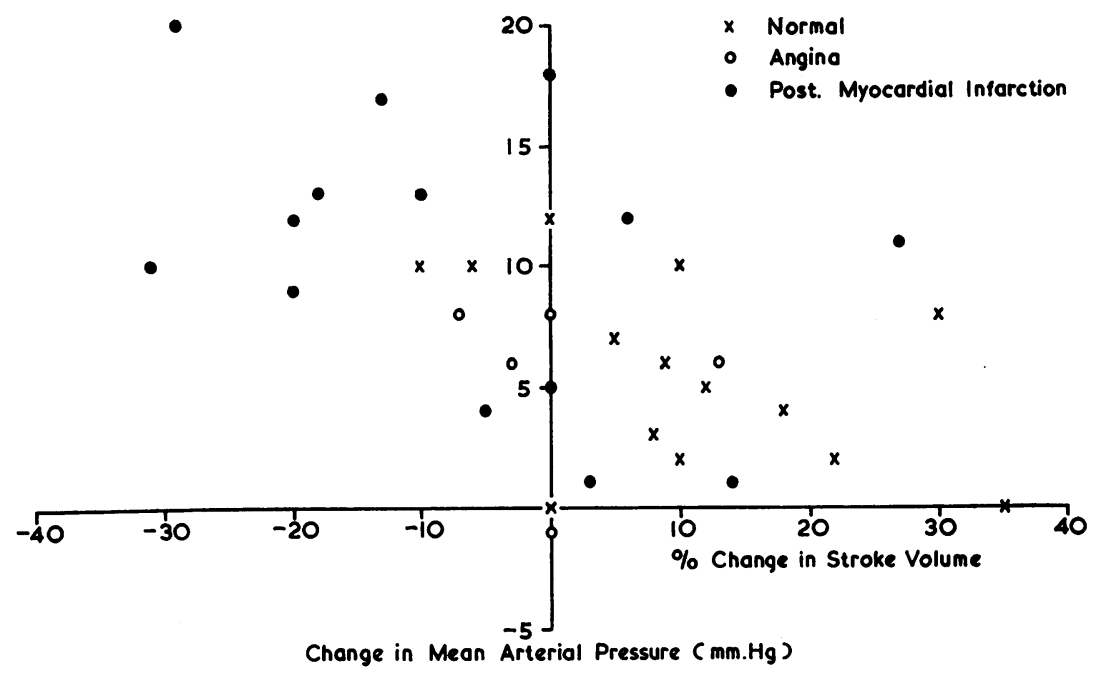

FIG. 7.-The effect on stroke volume of smoking one cigarette in relation to mean pressure change.

\section{Discussion}

An association between coronary arterial disease and cigarette smoking has often been suggested in the past. The frequency of abnormal ballistocardiogram recordings among patients with ischæmic heart disease when smoking was discussed by Henderson in 1953, and the comparatively rare "tobacco angina" has been recently reviewed in great detail by Oram and Sowton (1963). Recent epidemiological surveys have also shown an increased mortality from coronary artery disease among smokers (Hammond and Horn, 1954; Doll and Hill, 1956), though, as BronteStewart (1961) points out, the relation is not necessarily a causative one.

There is substantial evidence that the pharmacologically active ingredient of tobacco smoke, as far as its acute action on the cardiovascular system is concerned, is nicotine. The amount of nicotine absorbed into the blood-stream during cigarette smoking has been intensively studied and this work has been reviewed by Larson (1960).

Nicotine, whether administered intravenously or inhaled from tobacco smoke, produces on the cardiovascular system effects generally similar to those that occur on stimulation of the sympathetic nervous system. In the concentrations of nicotine attained in the blood during smoking these effects are probably produced indirectly via chemoreceptors rather than by direct ganglion stimulation (Comroe, 1960). There is also an increased secretion of catecholamines by the adrenal medulla as suggested by the work of Watts (1960) who has shown a significant increase in the urinary excretion of adrenaline during cigarette smoking in normal man. Burn and Rand (1958) have produced evidence that nicotine also causes release of noradrenaline from local stores in the heart; the chromaffin tissue in the human heart is in the vicinity of the coronary arteries, particularly the left (Busacchi, 1912).

The hæmodynamic changes recorded by ourselves among normal patients are in general agreement with those reported by other observers in this laboratory (Irving and Yamamoto, 1963). The significant feature of this study has been the appearance of a small group of patients who have all had myocardial infarctions and who have a reduction in both cardiac output and stroke volume on smoking, and in two cases this was associated with the sensation of dyspnœa. These hæmodynamic findings have not been previously reported.

Boyle et al. (1947) using the ballistocardiograph demonstrated an increase in heart rate, cardiac output, and systolic and diastolic pressure in 18 normal subjects following intravenous nicotine 
bitartrate, and found no statistically significant difference from 24 patients with coronary artery disease. However, although analysed statistically as a whole, the latter group was a heterogeneous collection including some patients with angina alone and others who had myocardial infarction. These workers commented on the striking individual variation in response noted among their patients, and described one 53-year-old man with recurrent angina and a history of heart failure in whom an intravenous injection of $2 \mathrm{mg}$. nicotine bitartrate $(0.6 \mathrm{mg}$. nicotine base) produced a reduction in cardiac output of over one litre per minute.

The problem remains as to why some patients who have had a myocardial infarction should have a striking fall in stroke volume and cardiac output on smoking. One possibility is that smoking reduces effective coronary blood flow. Bargeron et al. (1957), employing coronary sinus catheterization and the estimation of coronary blood flow in normal man by the nitrous oxide technique, demonstrated that cigarette smoking produced a significant increase in coronary blood flow and a reduction in coronary vascular resistance. Bellet et al. (1962) showed that in normal dogs nicotine produced an increase in coronary blood flow which was found to be as high as 125 per cent, on an average, over the control value. However, when one or both of the coronary arteries were narrowed by ligatures, the average increase in coronary flow was considerably less. The response of the coronary flow to nicotine was directly related to the degree of coronary narrowing: the greater the coronary impairment the smaller was the increase in coronary blood flow. Similarly, Regan, Hellems, and Bing (1960), repeating the work of Bargeron in patients with coronary arterial disease, studied the effects of cigarette smoking and found that although there was an increase of approximately 30 per cent in left ventricular work in 6 out of 7 patients, they observed no significant change in coronary blood flow or coronary arteriovenous oxygen difference. Studies on the isolated perfused hearts of rabbits rendered atherosclerotic (Travell, Rinzler, and Karp, 1960) have shown that greater quantities of nicotine were required to produce the secondary increase in coronary flow produced in normal rabbits, and that the increase in heart rate and contractile amplitude was quantitatively less in the atherosclerotic group. The failure of 5 of our patients to respond in the usual way to the positive inotropic effects of nicotine may be related to an insufficient increase in coronary blood flow to meet the increased metabolic requirements of the stimulated myocardium. Perhaps, more simply, the severely damaged myocardium may be unable to respond to the local release of noradrenaline, or the local stores of this substance may be destroyed as a result of myocardial disease (Raab and Gigee, 1955), although this alone would not account for a fall in stroke output.

The usual increase in cardiac output occurs in the presence of peripheral vasoconstriction produced by nicotine. There is no reason to believe that this latter response is diminished in patients with myocardial ischæmia, and an increase of peripheral vascular resistance could further reduce the effective stroke volume. The large increase in mean pressure demonstrated among those patients showing a fall in stroke volume may be an expression of this increase in peripheral vascular resistance.

Our results suggest that certain patients with ischæmic heart disease respond to cigarette smoking in an abnormal manner. Therefore, it seems prudent to advise patients who have had a myocardial infarction not to smoke. Not all patients respond in this manner, even following a substantial infarction as judged by electrocardiographic changes and a permanent fall in blood pressure; Case 3 reported above produced a striking increase in both cardiac output and stroke volume on cigarette smoking. It appears that the patients most likely to suffer a fall in cardiac output are the late middle-aged or elderly, and those with recurrent ischæmic episodes and a history of cardiac failure. Occasionally, as in two of our own cases, the patient may have noticed a growing reluctance to smoke and even dyspnœa on smoking. This hæmodynamic response may possibly bear some relation to the increased mortality from ischæmic heart disease among cigarette smokers.

\section{SUMMARY}

The effect of cigarette smoking on the cardiac output and stroke volume together with the blood pressure and heart rate has been measured in 14 normal subjects, 5 patients with angina, and 14 
following myocardial infarction. Normal men and those with angina in the absence of infarction behave similarly with an increase in pulse rate, mean pressure, stroke volume, and cardiac output. Some patients among the post-myocardial infarction group showed a marked fall in stroke volume and cardiac output while smoking. Two of these patients had recently reduced their smoking because of dyspnœa; one of these patients experienced dyspnœa during the smoking test.

We are grateful to Sister J. Child, Mrs. A Simmonds, and Miss J. Powell for technical assistance.

\section{REFERENCES}

Bargeron, L. M., Jr., Ehmke, D., Gonlubol, F., Castellanos, A., Siegel, A., and Bing, R. J. (1957). Effect of cigarette smoking on coronary blood flow and myocardial metabolism. Circulation, 15, 251.

Bellet, S., West, J. W., Müller, O. F., and Manzoli, U. C. (1962). Effect of nicotine on the coronary blood flow and related circulatory parameters. Circulat. Res., 10, 27.

Boyle, M. N., Wégria, R., Cathcart, R. T., Nickerson, J. L., and Levy, R. L. (1947). Effects of intravenous injection of nicotine on the circulation. Amer. Heart J., 34, 65.

Bronte-Stewart, B. (1961). Cigarette smoking and ischæmic heart disease. Brit. med. J., 1, 379.

Burn, J. H., and Rand, M. J. (1958). Action of nicotine on the heart. Brit. med. J., 1, 137.

Busacchi, P. (1912). I corpi cromaffini del cuore umano. Arch. ital. Anat. Embriol., 11, 352.

Comroe, J. H. (1960). The pharmacological actions of nicotine Ann. N.Y. Acad. Sci., 90, 48.

Davis, F. W., Scarborough, W. R., Mason, R. E., Singewald, M. L., and Baker, B. M. (1956). The ballistocardiographic cigarette test: Further observations. Amer. Heart J., 51, 165.

Doll, R., and Hill, A. B. (1956). Lung cancer and other causes of death in relation to smoking. A second report on the mortality of British doctors. Brit. med. J., 2, 1071.

Gabe, I. T., Tuckman, J., and Shillingford, J. P. (1962). Determination of relative changes in cardiac output from noncalibrated earpiece dye-dilution curves. Circulat. Res., 11, 405.

Hammond, E. C., and Horn, D. (1954). The relationship between human smoking habits and death rates. A followup study of 187,766 men. J. Amer. med. Ass., 155, 1316.

Henderson, C. B. (1953). Ballistocardiograms after cigarette smoking in health and in coronary heart disease. Brit. Heart J., 15, 278.

Irving, D. W., and Yamamoto, T. (1963). Cigarette smoking and cardiac output. Brit. Heart J., $25,126$.

Larson, P. S. (1960). Absorption of nicotine under various conditions of tobacco use. Ann. N.Y. Acad. Sci., 90, 31.

Oram, S., and Sowton, E. (1963). Tobacco angina. Quart. J. Med., 32, 115.

Pickering, G. W., and Sanderson, P. H. (1945). Angina pectoris and tobacco. Clin. Sci., 5, 275.

Raab, W., and Gigee, D. (1955). Norepinephrine and epinephrine content of normal and diseased human hearts. Circulation, 11, 593.

Regan, T. J., Hellems, H. K., and Bing, R. J. (1960). Effect of cigarette smoking on coronary circulation and cardiac work in patients with arteriosclerotic coronary disease. Ann. N.Y. Acad. Sci., 90, 186. .

Travell, J., Rinzler, R. H., and Karp, D. (1960). Cardiac effects of nicotine in the rabbit with experimental coronary atherosclerosis. Ann. N.Y. Acad. Sci., 90, 290.

Watts, D. T. (1960). The effect of nicotine and smoking on the secretion of epinephrine. Ann. N.Y. Acad. Sci., 90, 74. 